\title{
Ring Flipping of Seven-membered and Eight-membered Dithienodisila-heterocycles
}

\author{
In-Sook Lee, Young-Woo Kwak, Manik Kumer Ghosh, Joji Ohshita, ${ }^{*}$ and Cheol Ho Choi \\ Deparment of Chemistry, Kumgpook National Cniversity. Daegu 702-701, Korea. ${ }^{*}$ E-mail: wwkwahlahuachr \\ ${ }^{\dagger}$ Department of Applied Chemistry, Graduate School of Engineering, Hiroshima Lniversity. Higashi-Hiroshima 739-8527. Japan \\ Received October 26. 2007
}

\begin{abstract}
Ground state structures and ring flipping transition states of eight- and seven-membered silicon containing heterocyclic compounds such as dithienodisilacyclooctatriene and oxadithienodisilacycloheptadiene derivatives. respectively have theoretically been investigated. Although the bithienylene moiety of the derivatives does not change the ground state structures. they significantly increase the ring flipping barrier by $13-17 \mathrm{kcal} / \mathrm{mol}$ in the case of the eight-membered rings $(2,3$, and $\mathbf{4})$ in contparison with that of silicon containing heterocyclic compound 6. chosen as a model. The same moiety increases the flipping barrier of seven-membered ring (5) is only slightly ( $3.3 \mathrm{kcal} / \mathrm{mol}$ ) in comparison with that of model compound 7 . Hence, it has been concluded that not only the existing ring strain of eight-membered ring but also the bithienylene moiety collectively increases the ring flipping barrier so as to prevent such conformational changes explaining anomalous NMR behaviour of dithienodisilacyclooctatriene derivatives $(2-4)$. In contrast, the effect of substituents $\mathrm{R}^{1}$ and $\mathrm{R}^{2}$ at the olefinic carbons of the eight-membered ring on the flipping barrier tumed out to be mild.
\end{abstract}

Key Words : Dithienodisilaç̣clooctatriene. Oxadithienodisilacycloheptadiene. Ring flipping barrier. Twisting angle

\section{Introduction}

Ring flipping of cyclic systems represents the dynamic behavior of chemical compounds in media. In the investigation of variable-temperature ${ }^{1} \mathrm{H}$ and ${ }^{13} \mathrm{C}$ NMR spectra of 1,3.6-cyclooctatriene ${ }^{1}$, no dynamic NMR effect was observed below $-180^{\circ} \mathrm{C}^{16} \mathrm{~A}$ single resonance attributed to two methylene protons on the respective ring methylene carbon atoms in 1.3,6-cyclooctatriene (eight-membered ring) is due to rapid interconversion through a ring flipping. The conformational energy barrier for the ring inversion of $1.3,6$ cyclooctatriene was calculated to be only $4.1 \mathrm{kcal} / \mathrm{mol}$ above the ground state. ${ }^{1 \mathrm{~b}}$

On the other hand. the ${ }^{1} \mathrm{H}$ and ${ }^{13} \mathrm{C}$. NMR spectra of the eight-membered disilacarbocycles. 1,1.4,4-tetramethy $1-5,6$. 7,8-tetraphenyl-1.4-disilacycloocta-2,5,7-triene derivatives ${ }^{2.3}$ having phenyl substituents on the ring and 1.1,6.6-tetramethyl-1.6-dihydrotribenzo-[b,e,g][1.4]-disilocine ${ }^{+}$having a biarylene moiety such as a biphenylene. indicated that the two methyl groups on the silicon aton of these eightmembered disilacarbocycles were nonequivalent. This nonequivalence of the two methyl groups on the silicon atom in the compounds may be due to the steric repulsions between the methyl substituents on the silicon atom and the phenyl substitutents or biphenylene moiety of the eight-membered ring. The ${ }^{1} \mathrm{H}$ NMR spectrum of the two methyl protons on the silicon atom of the seven-membered ring of 2.2,7.7-tetramethyl-3.4,5.6-tetraphenyl-1-0xo-2,7-disila-3.5-cycloheptadiene having a flexible $\mathrm{Si}-\mathrm{O}$-Si noiety shows magnetically equivalent.

We recently have reported that the palladium-catalyzed reactions of 4,4.5,5-tetranethyl-2,7-bis(trimethylsilyl)dithieno[3.2-c:c:2',3'e]disilacyclohexadiene 1 with alkynes afforded dithienodisilacyclooctatriene derivatives $2-4$ of a eight-membered ring along with a small amount of oxadithienodisilacycloheptadiene derivative 5 of a sevenmembered ring (Scheme 1). ${ }^{\text {ta }}$ Such insertion reactions of alkynes into the silicon-silicon bond of acyclic and cyclic disilanes in the presence of a transition-metal catalyst have extensively been studied. ${ }^{7}$ The formation of 5 may be due to the oxidation reaction ${ }^{8}$ of the silicon-silicon bond of 1 with a trace of molecular oxygen, which we were unable to remove from the reaction mixture

We found from the ${ }^{1} \mathrm{H}$ NMR and ${ }^{12} \mathrm{C}$ NMR spectra that the two methyl groups on the respective silicon atoms of the alkyne-inertion products 2-4 containing bithienylene and olefinic moieties are nonequivalent, whereas the two methyl groups on the silicon atom of the oxygen-insertion product 5 containing a Si-O-Si moiety are equivalent. It was suggested that the nonequivalence of the two methyl groups on the silicon atom in compounds $2-4$ may be ascribed to the disilacyclooctatriene ring. which is significantly twisted. In fact the twisting angle of the disilacyclooctatriene ring of 3 is observed as $59.3^{\circ}$ by X-ray crystallographic analysis. ${ }^{6}$ On the other hand, a single resonance attributed to the two methyl groups on the ring silicon atom in compound $\mathbf{5}$ is presumably due to rapid interconversion through a ring flipping. To our knowledge. little interest have been shown in the examination of the conformational behaviour of seven-membered oxadisilacarbocycle and eight-membered disilacarbocycle such as oxadithienodisilacycloheptadiene and dithienodisilacyclooctatriene derivatives, respectively. In this paper. we report the ring flipping energy barriers of the alkyne-insertion products 2-4 (eight-membered ring) and the oxygen-insertion product $\mathbf{5}$ (seven-membered ring) as well as the reactant 1 (six-membered ring). Using computa- 


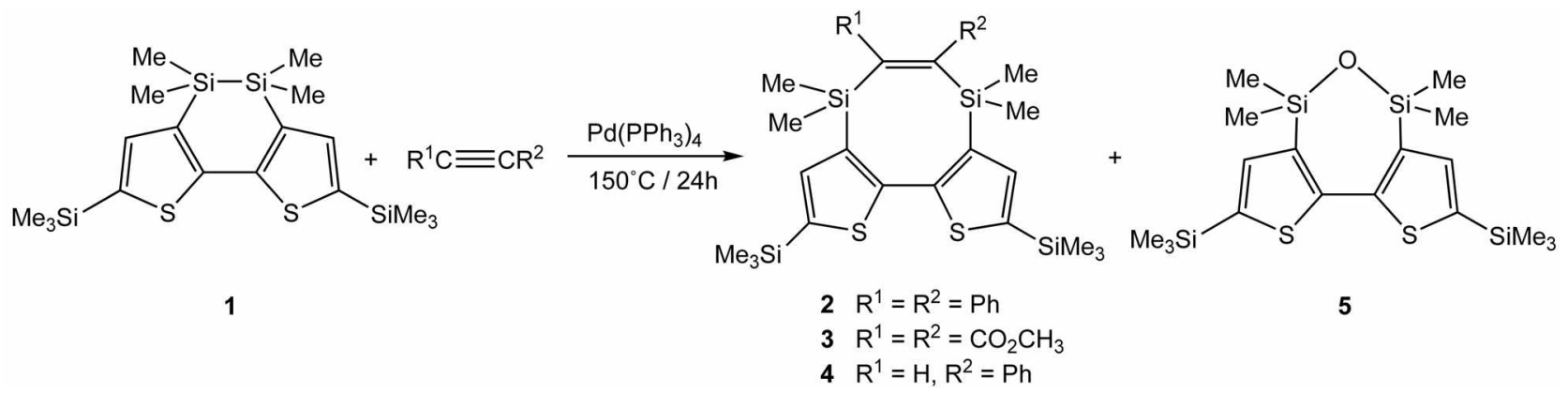

Scheme 1

tional analyses. current investigation attempts to examine the relations between the ring flipping and the anomalous NMR behavior of the SiMe 2 groups in the dithienodisilaheterocyclic derivatives $\mathbf{2 - 5}$

\section{Computational Details}

To obtain the conformational energy barriers, electronic structure calculations based on density functional theory were performed using B3LYP exchange-correlation functionals. All calculations reported here were performed with the GAMESS $^{10}$ (general atomic and molecular electronic structure system) electronic structure program. All-electron $6-31+\mathrm{G}(\mathrm{d}, \mathrm{p})^{\mathrm{jl}}$ basis set was used throughout the investigation. The Hessian matrix (matrix of energy second derivatives) was conputed and diagonalized for all stationary points to characterize them. Intrinsic reaction coordinate (IRC) calculations, using the Gonzalez-Sclulegel second order method, ${ }^{12}$ were conducted to verify that each saddle point connects minima of interest. All the computations were done without imposing symmetry unless otherwise specified.

\section{Results and Discussion}

As discussed in the introduction, the ${ }^{1} \mathrm{H}$ and ${ }^{13} \mathrm{C}$ NMR spectra for the alkyne-insertion products 2-4 indicate that the two methyl groups on the silicon atom of the eight-membered disilacarbocycle containing bithienylene and olefinic moieties are nonequivalent. whereas the two methyl groups on the silicon atom of the seven-membered oxadisilacarbocycle 5 containing bithienylene and $\mathrm{Si}-\mathrm{O}-\mathrm{Si}$ moieties are equivalent. The ${ }^{1} \mathrm{H}$ NMR spectra of $\mathbf{3}$ and $\mathbf{5}$ exhibit two resonances at -0.30 and $0.33 \mathrm{ppm}$. and a single resonance at $0.27 \mathrm{ppm}$. respectively which are attributed to the two methyl protons on the silicon atom. In the variable-temperature ${ }^{\mathrm{H}} \mathrm{H}$ NMR spectrum for the dithienodisilacyclooctatriene derivative 3. the two nonequivalent methyl protons on the silicon atom did not coalesce up to $60^{\circ} \mathrm{C}$ in $\mathrm{CDCl}_{3}$. How ever. the two methyl protons on the silicon atom of the oxadisilacarbocycle 5 were observed as a singlet at $-60^{\circ} \mathrm{C}$ in $\mathrm{CDCl}_{3}$ and even at $-100^{\circ} \mathrm{C}$ in $\mathrm{CD}_{2} \mathrm{Cl}_{2}$.

We firstly carried out DFT calculations on the structurally similar compounds 6 and 7 chosen as models (Chart 1) at the level of B3LYP/6-31+G(d.p) in order to know the overall

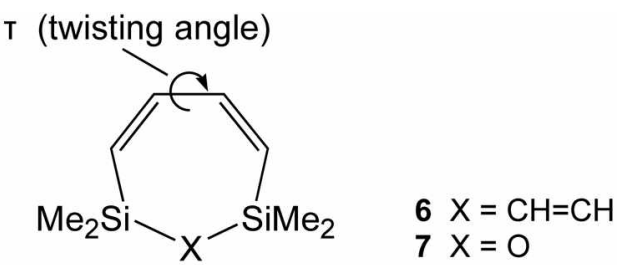

Chart 1. Model Compounds for MO Calculations.

energy changes with the twisting angle $(\tau)$.

The relative energy for the model compounds 6 and 7 is plotted as a function of the twisting angles of the butadiene unit of the optimized geometries in Figure 1.

As can be seen in the Figure 1, the flipping barriers were calculated to be 9.7 and $1.2 \mathrm{kcal} / \mathrm{mol}$ for disilacyclooctatriene 6 (circle) and oxadisilacycloheptadiene 7 (triangle), respectively. It clearly shows that the eight-membered ring of 6 has larger relative ring strain than the seven-membered ring of 7 at the ring flipping transition state. However, the difference in the flipping barriers between these two model compounds $(8.5 \mathrm{kcal} / \mathrm{mol})$ may not strongly implies the nonequivalence ${ }^{64}$ of the methyl groups on the ring silicon atom of the compounds 2-4. The ring flipping barrier can also depend on the biary lene moiety such as a bithienylene in the eight-membered disilacarbocycles 2-4 as well as the substituents $\mathrm{R}^{1}$ and $\mathrm{R}^{2}$. In order to investigate such substituent effects on the barrier. transition state calculations were done on the real insertion products $2-4$ and 5 . respec-

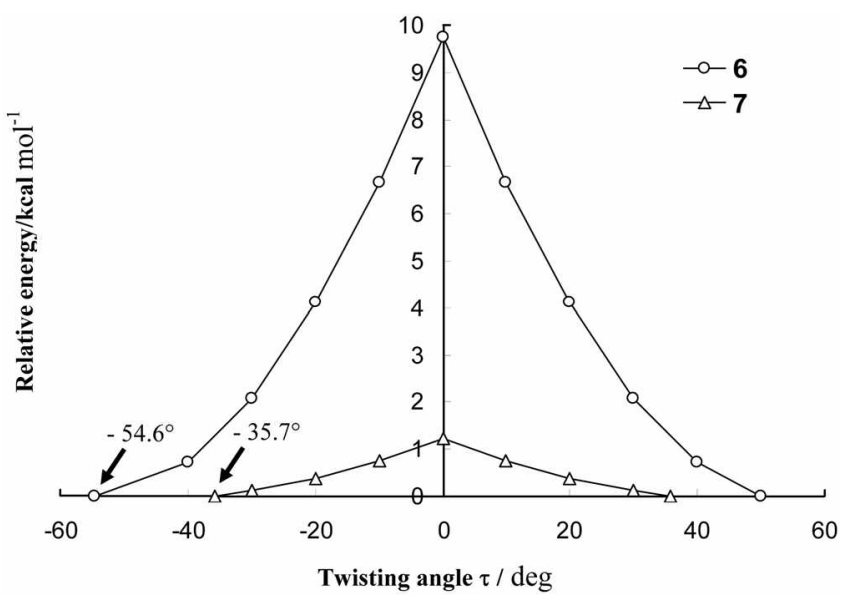

Figure 1. Relative energ derived from MO calculations at the $\mathrm{B} 3 \mathrm{LYP} / 6-3 \mathrm{I}+\mathrm{G}(\mathrm{d}, \mathrm{p})$ level for 6 (circle) and 7 (triangle). 


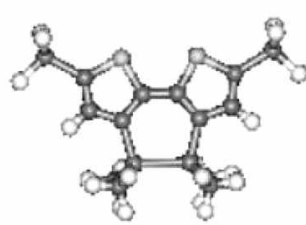

$1(\mathrm{TS}, \tau=1.6)$ $\Delta \mathrm{E}=0.3 \mathrm{kcal} / \mathrm{mol}$

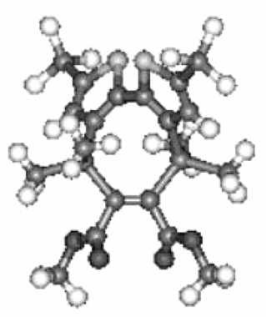

3 (Optimized, $\tau=57.6$ )

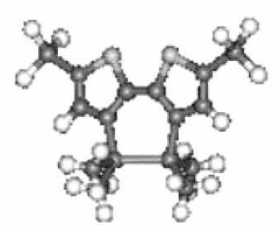

1 (Optimized, $\tau=19.4$ )

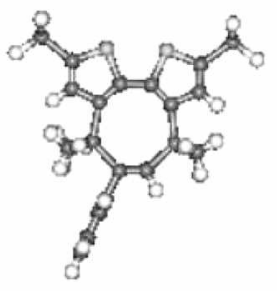

4 (TS, $\tau=1.3$ )

$\Delta E=22.6 \mathrm{kcal} / \mathrm{mol}$

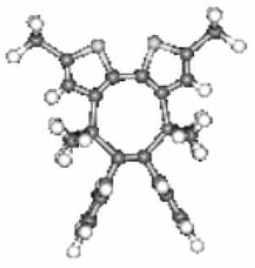

2 (TS, $\tau=1.4$ ) $\Delta \mathrm{E}=26.3 \mathrm{kcal} / \mathrm{mol}$

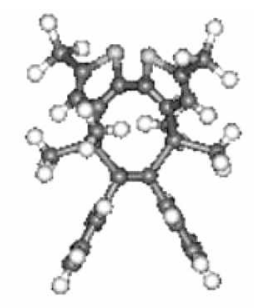

2 (Optimized, $\tau=57.1$ )

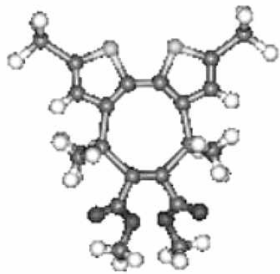

$3(\mathrm{TS}, \tau=9.3)$ $\Delta \mathrm{E}=24.5 \mathrm{kcal} / \mathrm{mol}$

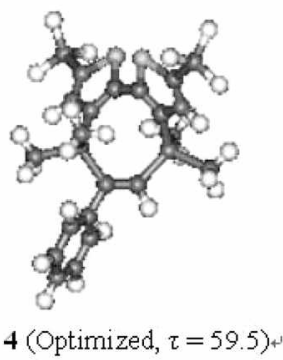

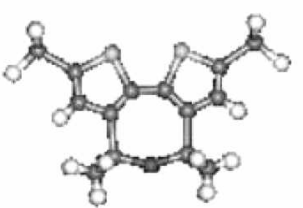

$5(\mathrm{TS}, \tau=1.3)$ $\Delta \mathrm{E}=4.5 \mathrm{kcal} / \mathrm{mol}$

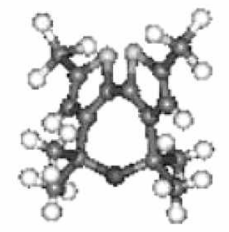

5 (Optimized, $\tau=39.0$ )

Figure 2. The optimized structures and the corresponding transition states of ring flipping conversions of 1-5. Optimized and TS stand for optinized structure and transition states, respectively. $\Delta \mathrm{E}=\mathrm{E}_{\tau}$ (transition state) - $\mathrm{E}_{0}$ (optimized structure). $\tau$ is the thisting angle of butadiene part of the ring, as depicted in Chart 1.

tively as well as on the initial reactant 1 with the level of B3LYP/6-3l+G(d,p). The results are presented in Figure 2.

Full geometry optimization on 1 (six-membered ring) yielded the twisting angle of $19.4^{\circ}$. which is relatively small. The flipping barrier of 1 was calculated to be $0.3 \mathrm{kcal} / \mathrm{mol}$. which is much snaller than those of model compounds 6 and 7 indicating that the ring flipping occurs very easily. It is seen that the bithienylene moiety of the six-nembered ring of 1 does not increase the flipping barrier. Table 1 summarizes ring flipping barriers, twisting angles of the optimized structures of $\mathbf{1 - 7}$ and observed twisting angles of 2.3 in comparison with that of the reactant 1.

Full geometry optimizations on the eight-membered disilacarbocycles of 2-4 containing bithienylene and olefunic moieties and the seven-membered disilacarbocycle of $\mathbf{5}$ containing bithienylene and $\mathrm{Si}-\mathrm{O}-\mathrm{Si}$ moieties yielded the twisting angles of $57.1^{\circ}, 57.6^{\circ} .59 .5^{\circ}$ and $39.0^{\circ}$. respectively. When compared to the twisting angle values of the eightmembered disilacarbocycle of $6\left(54.6^{\circ}\right)$ and of the sevenmembered oxadisilacarbocycle of $7\left(35.7^{\circ}\right)$ which do not have a bithieny lene moiety in the ring. the twisting angles of their corresponding real compounds $\mathbf{2 - 4}$ and $\mathbf{5}$ are increased to a negligible extent. implies that the introduction of the bithienylene moiety' in the ring does not have significant effects on the ring strain of ground state structures. It is seen that 5 has smaller twisting angle due to the less strained seven-membered oxadisilacarbocycle. The effect of substituents $R^{1}$ and $R^{2}$ of the olefinic carbons on the twisting angle is mild. since the twisting angles of 2-4 agree within $2^{\circ}$ with each other. The twisting angles of the eight-membered disilacarbocycles are in good agreements with the available experimental values of $54.28^{\circ}$ (2) and $59.32^{\circ}$ (3) by X-ray crystallographic analysis. ${ }^{\text {ta }}$ Encouraged by good agreements with experimental twisting angles, the transition states of ring flipping of 2-5 were calculated. The ring flipping barriers, defined as the energy differences between the transition state and the fully optimized structure of $\mathbf{2 - 5}$, were calculated to be $26.3,24.5 .22 .6,4.5 \mathrm{kcal} / \mathrm{mol}$. respectively. On comparing the flipping barrier value $(9.7 \mathrm{kcal} / \mathrm{mol})$ of the model compound 6, the ring flipping barriers of the real compounds $2-4$ are increased significantly. which are may be due to the steric repulsions between the methyl substituents on the silicon atoms and the bithienylene moiety of the eightmembered ring. However, the flipping barrier of $\boldsymbol{5}$ is increased only slightly as compared to the model compound 7 indicating that the ring flipping of 5 can still occur easily. It imply's that the Si-O-Si unit of the seven-membered ring 5 is very easy to bend for the ring flipping. Since the flipping barriers of 2-4 agree within $4 \mathrm{kcal} / \mathrm{mol}$, the effect of $R^{1}$ and $\mathrm{R}^{2}$ substituents on the flipping barrier is mild. In general. it is seen that the introduction of sterically bulky groups such as phenyl or bianylene groups into the eight-membered ring

Table 1. Ring flipping barriers, twisting angles of the optimized structures of 1-7 and observed twisting angles of 1-3

\begin{tabular}{|c|c|c|c|c|c|c|c|}
\hline & 1 & 2 & 3 & 4 & 5 & 6 & 7 \\
\hline ring flipping bariers $(\mathrm{kcal} / \mathrm{mol})$ & 0.3 & 26.3 & 24.5 & 22.6 & 4.5 & 9.7 & 1.2 \\
\hline twisting angles of optinized structures $\left({ }^{\circ}\right)$ & 19.4 & 57.1 & 57.6 & 59.5 & 39.0 & 54.6 & 35.7 \\
\hline observed twisting angles $\left({ }^{\circ}\right)^{\circ}$ & 20.2 & 54.3 & 59.3 & & & & \\
\hline
\end{tabular}

: determined by single-crystal X-ray crystallography (ref. 6 ) 
strongly increases the flipping barriers of transition states and it affects the eight-membered ring compounds $2-+$ more significantly than the seven-membered ring compound $\mathbf{5}$.

\section{Conclusions}

Ground state structures and ring flipping transition states of the initial reactant 1 . the eight-nembered disilacarbocycle derivatives 2-4, and the seven-membered oxadisilacarbocycle derivative 5 as well as their model compounds 6 and 7 were exanined to understand the relations between the ring flipping and the anomalous NMR behavior. According to the model compound studies. the flipping barrier of the eightmembered ring is larger than that of the seven-membered ring by $8.5 \mathrm{kcal} / \mathrm{mol}$. which is mostly due to the larger ring strain of the eight-mentbered ring. Although. the introduction of bithienylene moiety does not affect the twisting angles of the optimized structures to a larger extent, it significantly increases the ring flipping barrier of the eightmembered ring of compound $2-4$ by $13-17 \mathrm{kcal} / \mathrm{mol}$ in comparison with that of the model compound 6 . However. the same moiety slightly increases the flipping barrier of the seven-nembered ring of compound 5 by $3.3 \mathrm{kcal} / \mathrm{mol}$ in comparison with that of the model compound 7 . Since the flipping barriers of $2-4$ agree within $4 \mathrm{kcal} / \mathrm{mol}$. it is seen that the effect of $R^{1}$ and $R^{2}$ substituents at the carbon-carbon double bond of the disilacarbocycles $2-4$ is mild. Therefore. it is concluded that not only the existing ring strain of the eight-membered ring but also the bithienylene moiety collectively increases the ring flipping barrier so as to prevent such conformational changes. However, in the case of six- (1) and seven-membered rings (5), the bithienylene moiety does not affect the ring flipping barrier significantly.

Acknowledgments. The research has been supported by Korea Research Foundation Grant (No. KRF-2006-005J02401)

\section{References}

1. (a) Buemi, G.: Zuecarello, F.: Grasso, D. J. Hol. Shuct. 1977, t2.
195. (b) Anet. F. A. L.: Yavari. I. Tetratedton Letters 1975. 4221.

2. Sakurai. H.: Kamiyama. Y: Nakadaira. Y. J. Am. Chent. Soc. 1975. 97.931

3. Mochida. K: Wada, T.; Suzuki. K.; Hatanaka W.: Nishiyama, Y: Nanjo. M.: Sekine. A.: Ohashi, Y; Sakamoto, M: Yamamoto, A Bull. Chem. Soc. Jpn. 2001, 7f, 123 .

4. (a) Yoshida. H.: Ikadai. J.: Shudo. M.: Ohshita. T.: Kunai. A. $J$ Ant Chen Soc 2003. 125.6638. (b) Yoshida. H.: Ikadai. J.: Shudo. M.: Ohshita. J: Kunai. A. Orgonontetallics 2005. 2f. 156.

5. Nakadaira, Y; Sakurai, H. J. Organomet. Chem. 1973, 47.61

6. (a) Kwak, Y.-W.: Lee, I.-S.; Baek, M.K.: Lee, U.; Choi, H.J.; Ishikawa, M.: Naka, A: Ohshita. J.: Lee. K.-H.: Kunai. A. Organontetalics 2006. 25. 48. (b) Ohshita. T.: Nodono. M.: Kai. H.: Watanabe. T.: Kunai. A.: Komaguchi. K.: Shiotani. M.: Adachi. A.: Okita. K.: Harima. Y.: Yamashita. K.: Ishikawa. M. Organometallics 1999. 18. 1453 .

7. (a) Tamao, K.: Hayashi, T:- Kumada, M d. Organomet. Chem. 1976. 11, C 19. (b) Carlson. C. W. West, R. Organometallics 1983. 2. 1801 . (c) Seyferth. D.: Goldnnant. E. W.: Escudié. J. J. Organontet Chem. 1984. 271. 337. (d) Yamashita. H.: Tanaka. M. Chent. Lett. 1992. 1547. (e) Finckh. W.: Tang. B. Z.: Lough. A.: Manners, I. Organonetallics 1992, 11, 2904. (t) Kusukawa. T: Kabe. Y; Ando, W. Chem. Lett. 1993. 985. (9) Murakami, M; Yoshida. T.: Ito. Y. Organometallics 1994, 13. 2900. (h) Sharma. H. K.: Pantell. K. H. Chem. Rev: 1995. 95. 1351. (i) Horn. K. A. Chen Rev: 1995. 95. 1317. (j) Suginome. M.: Ito. Y. Chem, Rev 2000. 100. 3221. (k) Naka. A.: Yoshida. K.: Ishikawa. M. Miyahara. I; Hirotsu. K; Cha, S.-H; Lee, K.-K; Kwak, Y.W. Organonetallics 2001, 20. 1204. (I) Cha, S.-H.; Lee, K.-K: Kwak. Y.W. Choi. H.-J : Park. Y. S.; Naka, A.: Ishikawa. M Organontetalics 2001. 20. 3718. (m) Suginome. M.: Ito. Y. J. Organonet. Chent 2003. 685.218

8. (a) Ishikawa. M.: Ikadai. J.: Naka. A.: Ohshita. T.: Kunai. A.: Yoshizawa. K: Kang. S.-Y: Yamabe, T. Organometallics 2001 20. 1059. (b) Naka, A.: Ikadai. J.; Sakata, J.: Miyahara, I; Hirotsu. $\mathrm{K}$; Ishikawa, M. Organonetallics 2004. 23. 2397.

9. Espinosa. A.: Gallo. M. A.: Entrena. A.: Gómez. J. A. J. Mol. Strict. 1994.323.247.

10. (a) Schmidt. M. W.: Balbridge. K. K.: Boatz. J. A.: Elbert. S. T.: Gordon. M. S.: Jensen, J. H.: Koseki, S.: Matsunaga. N.: Nguven, K. A.; Su. S.; Windus. T. L.: Dupuis, M.: Montgomery. J. A. J. J. Comp. Chem 1993. 1t, 1347. (b) Fletcher, G. D.: Schmidt, M. W: Gordon. M. S. Ath Chem. Physics 1999. 110.267

11. Herhe. W. J.: Ditchfield. R.: Pople. J. A. J. Chem. Phws. 1972. 56. 2257.

12. (a) Gonzalez, C.: Schlegel, H. B. J. Phys. Chem. 1990. 94. 5523. (b) Gonzalez. C.: Schelegel. H. B. J. Chem. Plys. 1991, 95. 5853 